\title{
Avaliação de política em saúde mental sob o viés da alteridade radical
}

| ${ }^{1}$ Taís Bleicher, ${ }^{2}$ José Célio Freire, ${ }^{3}$ José Jackson Coelho Sampaio |

Resumo: Realizou-se pesquisa de tese em

História Social, sob a vertente da História Oral, com o objetivo de avaliar a política de saúde mental do município de Quixadá, no período de 1993 a 2012. Foram selecionados quatro depoimentos de pessoal diretamente responsável pela construção da política, em sua primeira gestão: o prefeito, o supervisor de serviço, um auxiliar de Enfermagem e um médico. Os depoimentos foram analisados utilizando como referencial teórico a ética da alteridade radical.

Consensualmente, os depoimentos apontavam para o entendimento de que, além de o paciente e sua família precisarem de cuidados, intervenções se faziam necessárias no sentido de apresentar a loucura à cidade, como forma de diminuir o preconceito. Sugere-se, a partir dos relatos dessa boa prática, a criação de um novo critério de avaliação dos serviços em saúde mental, qual seja, sua efetividade em gerar, na sociedade, novas formas de lidar com a diferença e com o outro.

> Palavras-chave: Atenção Psicossocial; Quixadá; ética; alteridade radical; avaliação em saúde.

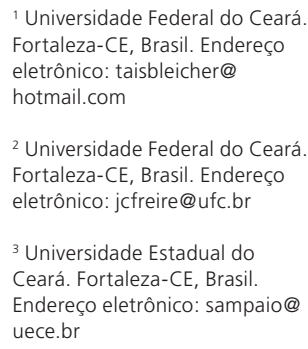

1 Universidade Federal do Ceará. Fortaleza-CE, Brasil. Endereço eletrônico: taisbleicher@ hotmail.com

${ }^{2}$ Universidade Federal do Ceará Fortaleza-CE, Brasil. Endereço eletrônico: jcfreire@ufc.br

${ }^{3}$ Universidade Estadual do Ceará. Fortaleza-CE, Brasil. Endereço eletrônico: sampaio@ uece.br

Recebido em: 18/01/2014 Aprovado em: 11/06/2014 
Este trabalho é oriundo da pesquisa de tese intitulada "A política de saúde mental de Quixadá, Ceará (1993-2012): uma perspectiva histórico-crítica e avaliativa de processo". O município de Quixadá se situa no sertão central do estado do Ceará, no nordeste brasileiro, e deu início à implantação de sua política de saúde mental no ano de 1993, com a criação de um Centro de Atenção Psicossocial (CAPS), o terceiro do estado. Desde então, ele se destaca no cenário nacional, seja nos eventos acadêmicos, por meio de produção bibliográfica a seu respeito, seja por sua influência no movimento brasileiro da luta antimanicomial.

Os CAPS são equipamentos legitimados administrativa e legalmente pelo governo público federal, por meio do Ministério da Saúde. Surgiram como experiências pontuais, no âmbito do Movimento Brasileiro de Reforma Psiquiátrica e, posteriormente, foram integrados ao projeto nacional. Hoje, existem mais de dois mil CAPS no país, pouco mais de uma centena no Ceará, realizando, sob o nome comum, experiências substitutivas ao modelo hospitalar-asilar, na perspectiva da atenção psicossocial territorial, influenciados pelo contexto geográfico, histórico e político-econômico dos lugares onde se situam. Em meio à diversidade dessas experiências, a trajetória do serviço de Quixadá parece se diferenciar em relação à dos outros, especialmente no que tange à intervenção social realizada e ao lugar destinado ao usuário do serviço dentro da sociedade, em um modelo de reabilitação que aponta para a necessidade de criação de mecanismos de avaliação em saúde mental que contemplem intervenções sociais orientadas para a boa convivência com a diferença.

A questão do respeito à diferença se encontra posta, de um ponto de vista ético, como filosofia da socialidade, na obra de Emmanuel Lévinas (1988). O filósofo franco-lituano situa a estrutura da subjetividade como responsabilidade por outrem. Trata-se de uma ética da alteridade radical, onde o outro ocupa um lugar privilegiado e nos obriga a responder a ele, ou seja, a sermos por ele responsáveis. Essa responsabilidade pelo outro, além de inalienável, é intransferível. Tal interpelação ética, mais do que um apelo, diz respeito a uma intimação, e sobressai efetivamente na relação com aqueles outros que nos são mais diferentes, como o louco, a exemplo do miserável, do órfāo, da viúva ou do estrangeiro referidos por Lévinas (1978). Nos limites deste texto, pode-se sintetizar a posição ético-política aqui assumida pelos autores como aquela que 
afirma que o usuário, na condição de outro para a equipe - gestor e trabalhadores

- seria respeitado como sujeito, ou seja, como aquele a quem se escuta em seu sofrimento e de quem nada se subtrai do seu mundo de vida.

Buscar-se-á, portanto, uma escuta ética da experiência de Quixadá, a partir dessa visada levinasiana, procurando identificar o reconhecimento do lugar do outro - na condição de louco -, que é concedido ao usuário; as implicações desse reconhecimento para os atores sociais envolvidos no serviço CAPS; e o papel exercido pela equipe, em sentido restrito, e pela comunidade, em um sentido amplo, na garantia dos direitos de cidadania do louco. Na esteira da discussão ética sobre atenção psicossocial (GODOY; BOSI, 2007; CARVALHO; FREIRE; BOSI, 2009; LEMOS; FREIRE, 2011), parte-se do estudo histórico de uma boa prática com vistas à reflexão sobre a avaliação de serviços.

\section{Metodologia}

Diante da projeção do CAPS de Quixadá, objetivou-se realizar um estudo histórico sobre a política de saúde mental daquele município, com um recorte temporal que engloba o seu nascimento, em uma determinada gestão municipal e as quatro gestôes municipais subsequentes. Com isso, seria possível avaliar também as mudanças ocorridas de acordo com o grupo que ocupava o poder à época.

Quanto ao referencial teórico da pesquisa, adotou-se a perspectiva da História Social, que toma como centro de sua análise o campo de forças da realidade social, na qual o sujeito tem um papel determinante na aspiração e construção de alternativas à realidade concreta (KHOURY, 2001). Não são abandonadas as dimensões das estruturas e dos condicionantes históricos, mas se dá um lugar especial à cultura e ao cotidiano, bases materiais e simbólicas das ações dos sujeitos.

A História Social permitiu o nascimento da História Oral, uma história do tempo recente, na qual as entrevistas são tomadas como documentos, e os fatos, a partir da perspectiva do sujeito, articulam-se com o "que pensávamos que éramos no passado, quem pensamos que somos no presente e o que gostaríamos de ser" (THOMSON, 1997, p. 57). A História Oral, assim como antes a História Social, dissolveu os limites entre a História tradicional e as outras disciplinas, aproximando o estudo histórico da Psicologia, Linguística, Economia e demais campos das humanidades (BURKE, 1997). Tal perspectiva permite, pois, a crítica do fenômeno histórico a partir da perspectiva filosófica da ética da alteridade radical. 
Para a pesquisa de tese, foi realizado levantamento bibliográfico, sobre as categorias-chave da pesquisa, e documental, sobre a legislação nacional e local em saúde e em saúde mental. Foram realizadas entrevistas por pautas com dois gestores municipais e três secretários de saúde, como convém à história política, assim como com quatro supervisores, 29 trabalhadores do período e três usuários do serviço de saúde e familiares, à maneira da História Social. No caso dos gestores, os temas das entrevistas foram: suas trajetórias pessoais e profissionais, com foco no período em questão; compreensão sobre saúde, saúde mental e trabalho em rede; relações entre gestor e trabalhador, e gestor e usuário do serviço de saúde; e condições de trabalho nos serviços de saúde municipais. No caso dos trabalhadores, além dos dois primeiros temas presentes nas entrevistas com os gestores, perguntou-se sobre o cotidiano da atuação, especialmente no que tange aos processos de trabalho e sobre sua visão acerca da participação comunitária, autonomia e cidadania dos usuários do serviço. Para os usuários e seus familiares, focalizou-se sua história de vida; vivências relativas ao processo saúde/doença mental; vivências de autonomia e cidadania no serviço e na cidade.

Assumir tal metodologia contribuiu para confrontar as diversas perspectivas dos grupos em questão e criar uma maior complexidade nos diversos níveis de análise. Devido ao caráter histórico da pesquisa, todos os entrevistados estavam informados, por Termo de Consentimento Livre e Esclarecido, de que não haveria sigilo quanto aos nomes, biografias e relatos, já que estas eram as informações fundamentais para a análise. $\mathrm{O}$ estudo, por ser abrigado em um Doutorado em Saúde Coletiva, seguiu os trâmites obrigatórios do Conselho de Ética e Pesquisa da Universidade Estadual do Ceará, recebendo parecer favorável de número 201.344.

Neste artigo, foi feito um recorte da pesquisa maior, utilizando as fontes orais para uma leitura crítica e interpretando-as a partir da ética da alteridade radical, como proposta por Emmanuel Lévinas. Tentou-se confrontar os elementos da experiência em foco com uma propositura ética que pressupõe a relevância do lugar do outro, no caso os usuários do CAPS - Quixadá, e uma escuta de seu sofrimento que represente a não indiferença em relação à sua diferença (LÉVINAS, 1992). Para isso, foram selecionadas as entrevistas que tratavam diretamente da construção alteritária da política, quais sejam: as do primeiro prefeito e primeiro supervisor do serviço, responsáveis por seu delineamento e, ainda, de um auxiliar de Enfermagem que trabalhou desde a fundação do serviço até os dias atuais 
e de um dos primeiros médicos. É de se destacar que a leitura levinasiana dos

fenômenos aqui descritos foi realizada pelos autores, não sendo uma propositura dos atores sociais entrevistados. A proposta de um modelo de avaliação pautada nesta perspectiva teórica também foi uma construção a posteriori, a partir da interpretação dos dados.

\section{Resultados}

O CAPS de Quixadá foi criado no ano de 1993, durante o mandato do prefeito José Ilário Gonçalves Marques, em meio a um grande projeto de municipalização da saúde e participação popular. Para tanto, foram utilizadas distintas estratégias, desde a modificação da forma de gestão dos recursos, adotando o modelo de gestão semiplena, na qual o município possui mais autonomia no controle da destinação das verbas federais (HEIMANN, 1998), a procedimentos e rotinas organizacionais, além da criação de mecanismos para a participação popular.

A gestão adotou o modelo de planejamento estratégico participativo situacional, que partia do governo e ia até os trabalhadores de todas as secretarias. Esse processo se dava de forma contínua, com realimentação de dados, para as avaliações e planejamentos seguintes (MARQUES, 2013, p. 08), apontando para um investimento na escuta, seja da equipe gestora, seja dos trabalhadores dos equipamentos públicos. Já se pode antever aqui a dimensão ético-política a que nos referimos na introdução, ou seja, a escuta do outro - no caso, gestores e trabalhadores dos vários equipamentos públicos - representa a saída de um modelo centralizador, onde o saber suposto e o poder que lhe corresponde se acham vinculados a um núcleo somente. A escuta pressupõe o sentido inverso, onde o periférico ou o que se coloca no fim da ação passa a ter força e seu conhecimento também é respeitado.

No que tange à população, foram criados ou efetivados vários mecanismos de participação popular. O Conselho Municipal de Saúde, que já existia, porém sem efetivo funcionamento, passou a fazer o controle, dentre outras coisas, dos gastos municipais em saúde. Nas conferências de Saúde, Educação, Social, Cultura, entre outras, discutiam-se políticas públicas específicas que, depois, eram levadas para o Congresso de Cidadania, que envolvia todas as áreas e, praticamente, o município todo, segundo José Ilário (MARQUES, 2013, p. 08). 
Pode-se dizer que a criação de tais estratégias, tanto no que tange à equipe política e aos trabalhadores, quanto no que tange à população, demonstram, por parte do gestor, uma permeabilidade à escuta. Uma maneira de gerir que possibilita a emersão de distintos discursos, que, mesmo conflitantes, podem apontar para uma construção coletiva comum. Foi com este solo político que se criou o CAPS de Quixadá.

No campo da saúde mental, o serviço apresentou como marca, também, uma atuação social. Esse deveria ser um dos diferenciais do serviço, já que o modelo de assistência psiquiátrica apresentou vertente marcadamente biologicista nas décadas anteriores à reforma psiquiátrica, no Brasil.

É verdade que o discurso biologicista não foi, historicamente, o único no campo. Se, no final do século XIX e início do século XX, o maranhense NinaRodrigues defendia premissas racialistas aplicadas à psicopatologia (ODA; DALGALARRONDO, 2011), essa defesa nunca se deu de forma pura. Mesmo em Nina-Rodrigues, a degenerescência era etiologia dos quadros de loucura, assim como o clima, as revoluções político-sociais, condições sanitárias pouco lisonjeiras, entre outras (NINA-RODRIGUES, 2011). Eminentes psiquiatras atacaram fortemente as teorizações que associavam o adoecimento físico ou mental à miscigenação, a raças específicas ou, ainda, ao clima tropical, como foi o caso de Juliano Moreira (MOREIRA; PEIXOTO, 2011).

O supervisor do CAPS de Quixadá, José Jackson Coelho Sampaio, estava atento a essa tensão no campo e suas consequências. Ao fazer um resgate sobre o seu percurso profissional e a epistemologia que justificou as suas práticas no campo, alinhou-se à Higiene Mental, tal qual defendida por Ulisses Pernambucano, segundo a qual "o transtorno mental é uma experiência existencial, não é só um destino biológico” (SAMPAIO, 2013, p. 04). Essa vertente da Higiene Mental, segundo ele, diferenciar-se-ia radicalmente da perspectiva da Higiene Moral autoritária, vivida no Rio de Janeiro, segundo a qual, "toda psicose, toda loucura, derivava de uma degeneração cerebral. E toda degeneração cerebral derivava da mistura racial. Então eles propunham, lá no Rio de Janeiro, a esterilização dos já loucos e o apartheid racial para evitar novos loucos" (SAMPAIO, 2013, p.04).

A teoria da degeneração tem suas origens no século XIX, com Morel, e associava, diretamente, degeneração à periculosidade, às perversas tendências do espírito e a deploráveis desvarios do coração humano. Nesse momento, a Psiquiatria 
serviu para aliar os conceitos de periculosidade, incurabilidade e cronicidade (DESVIAT, 1999), ainda presentes nas representações sociais sobre a loucura. Assim, se na Idade Clássica os loucos deviam ser excluídos do convívio, ao lado de outros indesejáveis (FOUCAULT, 1972), no século XIX e em meados do século $\mathrm{XX}$, tanto em países europeus como no Brasil, eles deveriam ser exterminados. A expressão máxima desse extermínio se deu através de decreto, em 1939, quando Adolf Hitler autorizou que médicos e psiquiatras realizassem a então chamada "morte de misericórdia”, destinada a doentes incuráveis, físicos e mentais.

El punto de partida es la pérdida o carencia de vida propiamente humana y, por tanto, de toda capacidad de decisión y discernimiento, lo que convierte tales vidas en insensibles (Hoche se encarga de reiterarlo) y en totalmente dependientes. Son una carga para la familia y para la sociedad, ya que sólo consumen los recursos que otros producen (PEREÑA, 2011, p. X).

Estudos posteriores revelaram que, durante o nazismo, entre 100 e 260 mil enfermos mentais foram mortos (PEREÑA, 2011), consequência direta do posicionamento psiquiátrico de então e desse decreto.

No Brasil, embora o genocídio nunca tenha sido uma política de Estado, estudos recentes apontam que, apenas no Hospício de Barbacena, morreram 60 mil internos, em um ambiente similar aos campos de concentração nazista:

Em 1960, havia 5 mil pessoas vivendo onde cabiam 200. Chegando lá, elas eram forçadas não só a abrir mão de sua identidade, mas também de sua condição humana. Recebiam outro nome, eram obrigadas a se vestir com trapos (e muitas vezes tinham de andar nuas mesmo durante os invernos frios da região), dormiam em camas de capim em meio à completa imundície, bebiam água do esgoto, passavam fome (e, quando comiam, eram refeições que talvez nem animais encarassem), apanhavam, levavam choques elétricos sem qualquer prescrição médica (e sem qualquer cuidado no procedimento, o que provocou a morte de muita gente) e alguns sofriam lobotomia, para ficar numa descrição sucinta (PRADO, 2013).

No Hospício de Barbacena, "[d]aquelas pessoas, 70\% não tinham nenhuma doença mental" (PRADO, 2013). Ou seja, o Brasil, sob o pretexto do tratamento da loucura, realizava o seu Grande Enclausuramento, à maneira da Idade Clássica Europeia, enquanto uma vertente higienista defendia os estados degenerados e a necessária esterilização dos enfermos, o que parece apontar para uma continuidade entre diversas formas de segregação e tentativas de aniquilação da loucura. Do ponto de vista teórico-crítico, trata-se da tentativa de destruição do outro, da eliminação da diferença e, portanto, de uma invertida do preceito ético do "não matarás", 
a que se refere Lévinas (1978). O mandamento ético "não matarás", de origem bíblico-judaico-cristã, é utilizado por Lévinas para explicitar a impossibilidade ética do assassínio, ou melhor dizendo, da eliminação da alteridade.

Até hoje, um dos grandes pontos de ação dos serviços de saúde mental deveria ser o esclarecimento a respeito das perspectivas teóricas atuais sobre o processo saúde-doença mental, em uma tentativa de combate às representaçóes sociais vigentes. Mais do que o esclarecimento, seria necessário propiciar o contato com a loucura, lugar da diferença - e não do perigo. Uma das atuações nesse sentido, supervisionada por José Jackson, é por ele descrita:

Tinha um pau danado, uma briga danada, numa reunião de supervisão porque a psicóloga e a terapeuta ocupacional diziam que aquela criança precisava de um trabalho de perceptomotricidade. Precisava, por exemplo, nadar. Aí eu dizia: 'Qual é a alternativa?'. 'Ah, tem que fazer uma piscina aqui'. Eu digo: 'Por que fazer uma piscina aqui? Será que nós não estamos reinventando o hospício, que tudo era feito dentro das muralhas do hospital, porque o cliente não podia circular pela cidade, não? Por que é que eu vou ter que dar o nome de piscinoterapia, para criar um piscino-dispositivo terapêutico aqui dentro do CAPS? Não, onde é que tem piscina na cidade?' Aí fomos atrás da Associação Atlética do Banco do Brasil. Foi a maior confusão, a princípio. Os sócios, a diretoria da $\mathrm{AABB}$ não queriam receber o cliente louco. Mas, aí nós fomos lá, fizemos uma apresentação, mostramos as novas teorias sobre psicose. Deixamos claro que psicose não é como dengue, não é como tuberculose, [risos] não tem a ver com esse espaço do infecto-contagioso, né? (...). Então a gente começou a fazer todo trabalho de perceptomotricidade e levar as crianças com algum grau de deficiência mental ou com transtorno psicótico pra fazer natação lá na AABB. Então, a ideia era fazer com que as pessoas circulassem pela cidade (SAMPAIO, 2013, p. 17).

A ideia de que as pessoas circulassem pela cidade era uma das principais estratégias para o combate ao estigma e para uma possibilidade de cidadania do psicótico. Wellington Peixoto de Sousa, que iniciou sua trajetória profissional no CAPS como auxiliar de Enfermagem e, posteriormente, se tornou técnico de Enfermagem e coordenador do serviço, relata que, ainda antes do CAPS ser inaugurado, foram realizadas supervisões para que os trabalhadores tivessem uma ideia de como iriam atuar - e, para ele, o principal da atuação do CAPS era acabar com o estigma (SOUSA, 2013, p. 13). Enquanto isso, para Carlos Magno Cordeiro Barroso, seu contemporâneo médico e, posteriormente, psiquiatra e supervisor do serviço, definiu como a principal questão do serviço a cidadania do psicótico.

Cidadania significa aqui ter um lugar na cidade. A cidade é de todos os cidadãos e cada um utiliza seus espaços de acordo com seus interesses, necessidades e desejos que devem ser respeitados por todos. Em outras palavras, trata-se de 
não estigmatizar e não segregar o louco. Ao se reconhecer a diferença, ao não ser indiferente a ela, todos se responsabilizam e todos passam a conviver, mas respeitando as singularidades. $\mathrm{O}$ outro, qualquer outro, é absolutamente outro, afeta seus outros a que têm de responder - ser responsáveis a ele (LÉVINAS, 1978).

Mas, como construir a cidadania do louco e em quais condições?

Então a sociedade, a cidade pequena, é um mundo variável de problemas, de cidadania prum lado, perda de cidadania de outro, de todos. Todos estão nesse movimento aí. Então, nós não temos essa ideia de criar um mundinho legalzinho pro paciente. Apesar de que algumas pessoas dizem assim: 'Ah, então quer dizer que só não indo pro hospício aí pronto, tá resolvido?'. Eu ouço isso como quem diz assim: 'Não, não tem que ir pro hospício, mas tem que ter grupinho de atividades, tem que fazer cestinha, tem que não sei o quê e tal e tal' [risos]. Então não ir pro hospício, no nosso caso, em Quixadá, significou ser jogado, jogado à cidade. E a gente radicalizou muitas vezes isso quando a gente insuflava alguns pacientes, por exemplo, a ir pras igrejas, [risos] a ir pras missas, que nunca iam. Então não era a gente cuidando. Se não vai pro hospício, então vai fazer o quê? Vai fazer o que todo mundo faz. Ou o que todo mundo não faz. É estar ali de igual, meio que igual. Eu lembro, durante muito tempo a gente ficava admirando, nós da equipe, alguns pacientes nossos que iam pro CAPS e voltavam. Tinham dois ou três, adultos, esquizofrênicos, que iam de mão dada na rua. Três esquizofrênicos, homens grandões [risos], de mãos dadas na rua, no sertão do Ceará. Então isso pra nós significa não ir pro hospício. Porque se a pessoa é aquilo ali, então, é permitir que seja. Outra frase que eu gosto muito de dizer é isso: 'Que o psicótico viva normalmente como psicótico' (BARROSO, 2013, p. 15).

O que significa estar ali "de igual" ou "meio que igual”? Estar ali de igual, jogado à cidade, sem nenhum cuidador, é o oposto de estar dentro do serviço de lógica manicomial, "fazendo cestinha". "Fazer cestinha" em um mundo "legalzinho" criado para o paciente, é a substituição do internamento por uma forma de serviço que insiste em que o paciente se vincule a uma lógica regressiva institucional, em lugares e tempos específicos. Esse lugar é diferente da polis, isto é, a cidade política, em que a palavra surge como direito de cada cidadão de se exprimir, de tornar pública a sua opinião (CHAUÍ, 2000). O cidadão psicótico está ali "meio que igual" na medida em que se apresenta em sua estranheza, adulto, andando de mão dada na rua. A partir de uma perspectiva ético-crítica podemos sair do âmbito do incomparável da filosofia da alteridade radical para o solo da justiça, ou seja, da comparação entre iguais, da equidade e da reversibilidade (LÉVINAS, 1978). Assim, no espaço da polis, o outro - o louco - se relaciona com seus outros, o que possibilita a comparação e a oferta de condições semelhantes para as relações entre os cidadãos. 
Nesse sentido, a microexperiência com os cidadãos usuários do CAPS alinhava-se com a experiência maior vivida na cidade de democratização da gestão, em que discursos diversos deveriam ter espaço, entrar em conflito, para a possibilidade do comum, da comunidade. Uma limitação que aparece aqui, em relação à continuidade de um trabalho que tenta garantir a cidadania e a condição de sujeito do louco, no âmbito de sua comunidade, é a alternância do poder e sua interferência nos equipamentos de políticas públicas. Nesse sentido, é visível a importância do componente ideológico na base dos programas desenvolvidos, em termos de sua assunção por parte dos trabalhadores e gestores.

No caso de Carlos Magno, a postura antimanicomial não surgiu da teorização acadêmica. Surgiu da perspectiva político-ideológica e só se aliou à teoria depois, por meio das supervisões com José Jackson. Essa postura lhe trouxe alguns embates com outros profissionais:

Eu estava discutindo com uma psicanalista e (...) com um psicanalista e eles tavam falando que: 'Não, mas, chega uma hora que não tem sujeito ali e você precisa intervir'. Aí eu disse: 'Pois, olhe, a intervenção na vida de um psicótico, normalmente, não é por um critério clínico, normalmente, é pelo incômodo que tá causando na família. Quando a família suporta bem, tem muitas pessoas que têm sua psicose'. Então até que ponto a gente pode dizer: 'Não, ali não tem mais um sujeito, eu vou intervir'? Os psicanalistas que eu tenho conversado têm falado sobre isso. E eu acho que esse modo de ver a psicose cria o hospício. Porque 'eu decido que ali não tem sujeito, porque a minha teoria diz que não tem sujeito’. Tudo bem, pode até não ter, mas eu não vou me guiar segundo esta crença ou esta verdade científica. O que nós estamos vendo em Quixadá é que é possível - não só em Quixadá - se guiar diante de um psicótico totalmente em crise procurando ali ainda um vínculo, uma conversa... (BARROSO, 2013, p. 15).

Surge a questão: onde está o sujeito? Numa perspectiva ética radicalizada, diz-se que o único sujeito de fato é o outro, que afeta, traumatiza e exige esforço (FIGUEIREDO; COELHO JR., 2004). Ou, pela forma invertida, que se é em relação a ele, sujeito, na condição de sujeitado. Se o outro, o louco, afeta os demais em sua interação, se há, portanto, uma intersubjetividade em jogo, como deixar de ser sujeito? O que parece existir aí, neste momento, é uma tentativa de omissão diante de um sujeito outro, diferente, estranho, que exige mais esforço de reconhecimento de sua diferença absoluta.

O relato feito por Carlos Magno acende as discussōes: a que servem as teorias sobre a loucura? Como se ligam a questôes ideológicas mais amplas? Quem decide se é preciso intervir ou não? O que está por trás do incômodo familiar, do 
Estado ou de qualquer grupo social? Como a aniquilação da diferença impede os avanços técnico e ético em relação à loucura? O que se trata, quando se trata uma doença mental? O que fazer diante de um psicótico?

Não enviar para os manicômios ou não deixar os psicóticos três dias por semana fazendo cestinhas não significa nada fazer. As ações que se desenvolveram no CAPS, para Carlos Magno, eram guiadas pela meta de não internação dos psicóticos em hospícios. A partir dessa meta, foi necessário criar uma metodologia. Este jeito de atuar dava ênfase à atuação com a sociedade, por meio da exposição do louco à sociedade, mas também por meio de esclarecimentos e suporte a diversos equipamentos sociais e às famílias. Ou seja, ao invés de rechaçar o louco, trata-se de responsabilizar-se por ele e de facilitar que sua família, seus amigos, sua cidade, responsabilizem-se por ele, garantindo que o louco não perca sua condição de sujeito, que tem voz e deve ser escutado.

Como se viu, a lógica da aniquilação da diferença está ainda presente no discurso de pessoas com alto grau de instrução. Está também presente no discurso de profissionais de saúde. Dentre as estratégias de expor a sociedade à psicose ou de combate ao estigma, Wellington Peixoto (SOUSA, 2013) se referiu a duas situações presentes no contexto do sistema de saúde. Ele defende que houve três momentos em relação à permeabilidade da cidade ao louco. $\mathrm{O}$ primeiro, anterior à atuação do CAPS, seria aquele no qual o discurso da sociedade seria: "o lugar do louco é no hospício”. Era o período das inúmeras transferências dos serviços de saúde de Quixadá para os hospitais psiquiátricos da capital, Fortaleza. O segundo, que, para ele, já foi sentido como um grande ganho, seria: "o lugar do louco é no CAPS". Finalmente, o momento atual, que seria "o lugar do louco é na sociedade", fruto da atuação do CAPS. O que temos aqui é uma reaproximação do outro, do louco, um retorno à sua casa. A morada serena e confiada, ou ethos, é o lugar da acolhida e da abertura (LÉVINAS, 1988), bem como de restauração física e psíquica. É o lugar do cuidado, par excellence, do ocupar-se do mundo, do preocupar-se em ser e do projetar.

Nesse segundo momento, embora a população reconhecesse a diferença entre o hospício e o CAPS, este ainda permanecia como lugar de segregação. Assim, o usuário do CAPS que adoecesse de uma enfermidade que não fosse mental, não deveria ter acesso aos equipamentos de saúde cotidianos da população. Seu atendimento deveria ser feito no próprio CAPS, independente da especialidade. 
Seria a reinvenção do hospício, nas palavras de Jackson Sampaio. Um hospício ambulatório, um hospício-dia, um hospício aberto ou poroso, um hospício humanizado - mas, ainda assim, um hospício.

A segunda situação citada por Wellington Peixoto foi quanto ao atendimento da crise psicótica. No município de Quixadá, antes das intervenções do CAPS, esse procedimento não existia no Hospital Geral, mesmo que houvesse condiçôes técnicas para tanto. $\mathrm{O}$ estigma relacionado à loucura estava presente nos próprios profissionais do hospital. As intervençôes se deram das seguintes maneiras: "Daí já surgia a ideia de trabalhar com o profissional de fora, e não o CAPS ter, pra cada patologia, uma profissão, assim: se precisasse do odontólogo, trazer o odontólogo, se precisasse de um fisioterapeuta, trazer o fisioterapeuta. Não, nossa ideia é que se levasse o paciente pra fora (SOUSA, 2013, p. 05)", e, ainda:

Até então eu (...) passava a noite no Hospital Eudásio Barroso e no dia seguinte eu tava no CAPS. Mas, no Eudário Barroso, como é que a gente ficava? O paciente estava agudizado, mas, geralmente... Não, 100\% de certeza (...) Também tava com acompanhante, pra não perder o elo com a família, e, a cada medicamento, a cada procedimento que a gente ia fazer com o paciente, eu tinha um técnico ou auxiliar de Enfermagem do meu lado, que aí eu já aproveitava e já capacitava (SOUSA, 2013, p. 03).

As açôes se focavam, portanto, em mostrar que era possível a convivência e a atenção em saúde ao paciente psicótico. Mesmo que, nas palavras de Carlos Magno, ele fosse "jogado à cidade", havia uma equipe que apoiava, dava suporte às ações e as realizava dentro de uma estratégia.

\section{Discussão}

O fim dos manicômios não significa o fim da lógica manicomial ou da necessidade humana de criar tipos que representam o perigo (GOFFMAN, 2012). A reforma psiquiátrica brasileira foi corajosa e avançou socialmente quando iniciou, legal e factualmente, a extinção dos manicômios, um avanço em relação a experiências de muitos países industrializados. As grandes revoluçôes históricas sempre são realizadas por pequenos grupos, enquanto que a população acompanha as mudanças em tempos diferentes, rearticulando-as com seus entendimentos e vivências anteriormente construídos. Este não é um processo natural. Quando se pensa em políticas públicas de saúde, há um fazer que possibilite que a sociedade acompanhe as mudanças da melhor maneira possível. 
Os profissionais que estiveram à frente da reforma psiquiátrica brasileira, por motivos diversos, compreendiam que não era mais possível tolerar a existência dos manicômios, seja pelos aspectos éticos - as diversas formas de violência sofrida pelos internos; seja pelos aspectos técnicos - o isolamento, ao contrário de favorecer a cura, cronificava o paciente; seja pelos aspectos financeiros manter a hospedagem de pessoas meses, anos ou mesmo uma vida inteira nos manicômios era muito oneroso aos cofres públicos. Embora fora e dentro do Brasil já houvesse algumas experiências exitosas de atenção em saúde mental não manicomiais, muito era necessário criar, isto é, descobrir fazendo. Assim, mesmo sob o mesmo signo, os CAPS se constituíram de maneira diversa ao longo do território nacional. Alguns se aproximaram da lógica do hospital-dia: eram oferecidos serviços ambulatoriais e os pacientes poderiam recorrer a eles livremente, sem internação, aos moldes de um centro de especialidades em Saúde Mental. Outros, embora abertos, repetiam a lógica manicomial: o paciente deveria ser obrigado a realizar determinadas atividades, por vezes de forma alienada, levando necessariamente à associação com o entendimento pineliano de que seria necessário destruir as ideias delirantes, distraindo o louco com o trabalho ou por meio de atividades como audição de músicas ou leituras (CAZETO, 2001). Esse discurso pré-científico aliar-se-ia a tratamentos de especialidades acadêmicas. De qualquer maneira, tanto no primeiro quanto no segundo modelo de CAPS aqui elencados, a atuação se daria sobre o usuário, que deveria se adequar à sociedade existente, por meio de uma normalização possibilitada pela medicação; pelas oficinas - que nem sempre se constituem como terapêuticas, mesmo que se proponham a isso; pelo ensinamento/ordenamento do usuário sobre o que fazer, como utilizar seu tempo livre e com quem.

O CAPS de Quixadá buscou, claramente, opor-se a esses modelos de serviços. Seu entendimento sobre Atenção Psicossocial Territorial tem um marco em uma experiência maior, democrática, de possibilidade de escuta e convivência com a diferença. Isso se construiu coletivamente nas supervisões do serviço mesmo antes de sua inauguração, formando um discurso coletivo e possibilitando a experimentação de metodologias diversas para que a cidade experimentasse a convivência com a diferença, nesse caso, representada pela loucura. O usuário também poderia experimentar a si mesmo, em outro espaço que não o institucional, sem o perigo de ser violentado pela cidade. O CAPS de Quixadá, 
por meio de seus esclarecimentos à população, sua atuação junto a equipamentos sociais, públicos ou privados, e seu apoio às famílias e às equipes de saúde, possibilitava que essa mudança social efetivamente acontecesse.

Isso leva, necessariamente, à reflexão sobre as distintas formas de se fazer reabilitação social. Quem deve ser reabilitado? É o psicótico que deve se tornar habilitado a conviver com a sociedade como esta está ou a sociedade deve estar habilitada a conviver com as diversas formas de diferença? A experiência de Quixadá e nossa leitura teórica nos levam ao entendimento de que é possível criar um modelo de Atenção Psicossocial que, primeiramente, não restrinja sua atuação às intervenções sobre o usuário. Seguindo esse raciocínio, a avaliação desse serviço também não pode se restringir aos dados sobre o paciente: sua evolução diagnóstica, número de atividades às quais está vinculado no CAPS, número de atendimentos, nem tampouco às práticas de gestão do serviço, processos de trabalho e tarefas realizadas; ou, ainda à capacitação de seus profissionais, suas condições de trabalho e carreira e seu entendimento sobre saúde-doença mental. Todos esses elementos se articulam em uma realidade complexa e podem, certamente, dizer algo. Mas há uma dimensão fundamental que deve ser levada em conta na avaliação de serviços de saúde mental que é sua efetividade em gerar, na sociedade, novas formas de lidar com a diferença e com o outro. Nesse sentido, independente do instrumental técnico adotado para análise, este deve apreender: em que medida a sociedade, em termos comportamentais, permite a circulação do paciente psicótico em seus diversos espaços? De que forma isso se dá: de maneira violenta ou respeitando essa outra maneira de ser? Quais práticas lhe são destinadas? Existe autonomia para que o usuário realize as atividades que julgue adequadas, mesmo que não sejam dentro do espaço do CAPS ou tuteladas? Quais são os discursos construídos sobre a loucura e a psicose? Em que medida servem para constituir lógicas segregadoras ou para efetivar os pressupostos da Atenção Psicossocial? Que intervençóes são realizadas pela equipe que buscam possibilitar uma maior permeabilidade à diferença? De que maneira essas ações se articulam com uma lógica maior de exercício de cidadania?

Todas essas questôes devem enfatizar que a forma de lidar com o outro deve caminhar na contramão de uma intervenção que visa eliminar a diferença ou totalizá-la, já que a alteridade, em sua forma radicalizada, não pode - e nem deve - ser eliminada. As diversas formaçóes profissionais ligadas à saúde mental 
não podem abrir mão da preocupação ética e de suas competências técnicas em

nome de proposituras morais sobre um modo ideal de existência. O cuidado como escuta do outro, de suas necessidades e de suas potencialidades, está implícito na proposta que representa, não uma desresponsabilização, mas pelo contrário, um responsabilizar-se pelo outro - o louco neste caso - a ponto de não aceitar a tentativa de eliminação, sempre frustrada, de sua alteridade. Responder ao outro, portanto, é confirmar sua condição de sujeito, singular, mas também social - um cidadão. ${ }^{1}$

\section{Referências}

BARROSO, C.M.C.: depoimento. [22 mar. 2013]. Entrevistadora: Taís Bleicher. Quixadá: CAPS Geral de Quixadá. 6 arquivos digitais mpg (1h17min27s). Depoimento concedido ao projeto: A política de saúde mental de Quixadá, Ceará (1993-2012): uma perspectiva histórico-crítica e avaliativa de processo, 2013.

BURKE, P. A Escola dos Annales (1929-1989): a Revolução Francesa da Historiografia. São Paulo: UNESP, 1977. 153 p.

CARVALHO, L.; FREIRE, J. C.; BOSI, M.L.M. Alteridade radical: implicações para o cuidado em saúde. Physis: Revista de Saúde Coletiva, Rio de Janeiro, v. 19, n. 3, p. 849-865, 2009.

CAZETO, S.J. A constituição do inconsciente em práticas clínicas na França do século XIX. São Paulo: Escuta, 2001. 357 p.

CHAUÍ, M. Convite à filosofia. São Paulo: Ática, 2000. 567 p.

DESVIAT, M. A reforma psiquiátrica. Rio de Janeiro: Fiocruz, 1999. 166 p.

GODOY, M.G.C.; BOSI, M.L.M. A alteridade no discurso da Reforma Psiquiátrica brasileira face à ética radical de Lévinas Physis: Revista de Saúde Coletiva, Rio de Janeiro, v. 17, n. 2, p. 289-299, 2007.

GOFFMAN, E. Estigma: La identidade deteriorada. Buenos Aires: Amorrortu, 2012. 183 p. HEIMANN, L.S. et. al. A descentralização do Sistema de Saúde no Brasil: uma proposta de investigação sobre o impacto de políticas. São Paulo: Instituto de Saúde, 1998. 86 p.

KHOURY, Y.A. Narrativas orais na investigação da História Social. Projeto História: São Paulo, v. 22, p. 79-103, 2001.

LEMOS, P.M.; FREIRE, J. C. Os contornos tardo-modernos do sofrimento e do adoecimento psíquico: proposições éticas para o Centro de Atenção Psicossocial. Psicol. rev. (Belo Horizonte), Belo Horizonte, v. 17, n. 2, 2011.

LÉVINAS, E. Totalidade e infinito. Lisboa: Ed. 70. 1988. 176 p. . Autrement qu'être ou au delà de l'essence. Paris: Le Livre de Poche, 1978. 288 p. . De dieu qui vient à l'idée. Paris: Vrin, 1992, 270 p. 
MARQUES, J.I.G.: depoimento [26 mar. 2013]. Entrevistadora: Taís Bleicher. Fortaleza: Assembleia Legislativa do Estado do Ceará. 3 arquivos digitais mpg (56min50s). Depoimento concedido ao projeto: A política de saúde mental de Quixadá, Ceará (1993-2012): uma perspectiva histórico-crítica e avaliativa de processo, 2013.

MOREIRA, J.; PEIXOTO, A. As doenças mentais nos climas tropicais (1906). In: BAYARDO, S.J.V.; MALPICA, C.R.; LARA, J.G. (Orgs.). Antología de textos clásicos de la psiquiatría latinoamericana. Guadalajara: Gladet, 2011, p. 125-136.

NINA-RODRIGUES, R. A loucura epidêmica de Canudos: Antônio Conselheiro e os jagunços (1897). In: BAYARDO, S.J.V.; MALPICA, C.R.; LARA, J.G. (Orgs.). Antología de textos clásicos de la psiquiatría latinoamericana. Guadalajara: Gladet, 2011, p. 111-119.

ODA, A.M.G.R.; DALGALARRONDO, P. Raimundo Nina-Rodrigues e as loucuras epidêmicas no Brasil. In: BAYARDO, S.J.V.; MALPICA, C.R.; LARA, J.G. (Orgs.). Antología de textos clásicos de la psiquiatría latinoamericana. Guadalajara: Gladet, 2011, p. 99-100.

PRADO, A.C. Livro traz testemunhos de genocídio no maior hospício do Brasil. Disponível em: <http://super.abril.com.br/blogs/como-pessoas-funcionam/livro-traz-testemunhos-degenocidio-no-maior-hospicio-do-brasil/>. Acesso em: 18 jan. 2014.

SAMPAIO, J.J.C.: depoimento [23 fev. 2013]. Entrevistadora: Taís Bleicher. Fortaleza: Residência de José Jackson Coelho Sampaio. 3 arquivos digitais mpg (1h51min59s). Depoimento concedido ao projeto: A política de saúde mental de Quixadá, Ceará (19932012): uma perspectiva histórico-crítica e avaliativa de processo, 2013.

SOUSA, W.P. de: depoimento [20 mar. 2013]. Entrevistadora: Taís Bleicher. Quixadá: CAPS Geral de Quixadá. 4 arquivos digitais mpg (1h3min51s). Depoimento concedido ao projeto: A política de saúde mental de Quixadá, Ceará (1993-2012): uma perspectiva histórico-crítica e avaliativa de processo, 2013.

THOMSON, A. Recompondo a memória: questôes sobre a relação entre a História Oral e as memórias. Proj. História, v. 15, p. 51-84, 1997.

\section{Nota}

${ }^{1}$ T. Bleicher e J.C. Freire participaram da concepção; coleta, análise e interpretação dos dados; redação e aprovação da versão final do artigo a ser publicada. J.J.C. Sampaio participou da orientação e revisão crítica relevante ao conteúdo intelectual e aprovação da versão final do artigo. 


\section{Abstract}

\section{Mental health policy evaluation under the radical alterity viewpoint}

We conducted thesis research in Social History, under the aspect of Oral History in order to assess the mental health policy of the city of Quixadá, Brazil, from 1993 to 2012. Testimonials from four directly responsible personnel were selected for the construction of politics in their first term: the mayor, the service supervisor, a nursing assistant and a physician. The interviews were analyzed using as a theoretical ethics of radical otherness. Consensually, the testimonies pointed to the understanding that, in addition to the patient and his family need care, interventions were necessary in order to present to the city madness as a way to reduce prejudice. It is suggested, based on the reports of this good practice, the creation of a new criterion for the evaluation of mental health services, namely, its effectiveness in generating, in society, new ways of dealing with difference and with each other.

> Key words: Psycho-social Care; Quixadá city ; ethics; radical alterity; health assessment. 